\title{
Glossary
}

\section{Ethics in epidemiology and public health I. Technical terms}

\author{
D L Weed, R E McKeown
}

Ethics in epidemiology and public health has emerged from several sources: most obvious is the discipline of bioethics, with its theories, methods, case studies, and familiar textbooks. Bioethics has primarily been focused upon medical ethics and research ethics and only recently has turned its attention to public health. Another source of scholarship is philosophical ethics. Here the sourcebooks are the writings of Aristotle, Kant, Mill, Rawls, and many others, the so called "high ground" philosophers of the past 2000 years. ${ }^{1}$ Philosophical ethics provides a rich lode from which to mine theories and concepts and to observe intellectual trends. A third source for ethics in epidemiology and public health is closer to home and is not so closely connected to bioethics nor philosophical ethics. Public health practitioners and scholars have written about the ethical problems that underlie professional practice. Advocacy, coercion, and scientific misconduct are a few representative examples, but there are many others, including privacy, conflicts of interest, and the rights of vulnerable communities.

Given the scope and connectedness of these sources, a vast number of words and phrases could be included in a glossary on ethics in epidemiology and public health. To organise what could be a very long list, we identify two categories of terms. There are the more technical terms of ethics, such as casuistry, communitarian ethics, obligations, and virtues. These we define below in the first installment of the glossary. There are also more applied termsequipoise, informed consent, privacy and the precautionary principle-representing important practical issues with significant ethical content. These will appear in a second installment. As the discipline of public health ethics matures, we expect to see many other terms surface. More importantly, we hope to see more scholarly discussions of ethical issues.

Office of Preventive Oncology, Division of Cancer Prevention, National Cancer Institute, EPS T-41, 6130 Executive Blvd, Bethesda, MD 20892-7105, USA

Correspondence to: DrWeed (dw102i@nih.gov)

Accepted for publication 13 June 2001

Autonomy (see also: Respect for Persons)

Literally, self ruling. Related to, and sometimes used in lieu of the bioethical principle of respect for persons. Implies intentionality and freedom from coercion. In the Kantian tradition, autonomy implies freely embracing a moral obligation. ${ }^{2}$ In public health, individual autonomy may be limited by interventions applied to populations. ${ }^{34}$
Beneficence (see also: Prima facie, Principles and Principlism, Utility and Utilitarianism) Literally, doing good; in bioethics, a prima facie principle underlying utilitarian approaches. Implies an obligation to promote benefits of things judged to be good, typically balancing produced goods against risks or harms. In public health, beneficence implies acting in the best interest of the population or society as a whole. $^{56}$

\section{Bioethics (see also: Ethics)}

A field of inquiry and academic discipline at the intersection of ethics and the life sciences. ${ }^{7}$ Emerging with an emphasis upon problems faced in the practice of medicine and biomedical research, bioethics has overlapping areas of scholarship and application: theory and method, clinical practice, regulatory policy, research practice, cultural and social concerns, ${ }^{8}$ and recently, public health and epidemiology. ${ }^{9}$

Case or Case study (see also: Casuistry)

A detailed description of a concrete situation requiring ethical analysis and a resultant judgment or action. Cases provide specific circumstances involving a patient (in medical ethics), a study participant or group (in research ethics) or a population (in public health ethics). Cases are typically grouped by subject matter and as such represent the input to the methods of practical ethical reasoning. ${ }^{10}$

Casuistry (see also: Case or Case study, Principles and Principlism, Specification) A method of practical ethical reasoning emphasising particular cases over theories or principles. From paradigm cases and the selection of morally relevant maxims indicating the right judgment or action, the user of casuistry finds generalisable guidance for judgments and actions when confronted with similar cases. Casuistry is not incompatible with the methods of principlism and specified principlism. ${ }^{11-13}$

\section{Communitarian ethics}

An approach to ethics emphasising communal values, the common good, social goals, and traditional practices. Closely aligned with the cooperative virtues and a community's shared understanding of the good life. Often pitted against liberal individualism (that is, rightsbased approaches) in its militant forms, a moderate communitarian view makes room for individual rights. ${ }^{41415}$ 
Deontological (see also: Respect for persons)

A duty-based theoretical approach to ethics, associated with the philosopher Kant. Right actions stem from freely embraced obligations to universal moral imperatives, such as the obligation to respect persons as ends and not as means. $^{25}$

Ethics (see also: Bioethics)

A philosophical discipline concerned with understanding how human beings should act, what is good, and what kind of life is best.

Fustice (see also: Prima facie, Principles and Principlism)

In bioethics, a prima facie principle implying equity or fairness, especially regarding the fair distribution in the population of benefits and risks of research, health care, or other goods. Contrasted with retributive justice operating in the criminal justice system. ${ }^{16}{ }^{17}$

Non-maleficence (see also: Beneficence, Prima facie, Principles and Principlism)

Literally, not causing harm. A prima facie principle in bioethics, sometimes subsumed under the principle of beneficence. An obligation traditionally at the heart of medical ethics - the "first do no harm" component of the Hippocratic Oath-non-maleficence can be seen as distinct from the obligation to produce good.

Obligation (see also: Principles and

Principlism, Rights)

Used interchangeably with duty. That which is required, although tempered by competing duties. Obligations are correlated with rights. In epidemiology and public health, professional role obligations derive from basic ethical principles and are articulated in codes of professional conduct.

Prima facie (see also: Principles and Principlism, Specification)

A term used to describe bioethical principles as neither rules of thumb nor absolute prescriptions but rather as binding in all cases unless an obligation found in one principle conflicts with another. In such situations, balancing of competing principles is undertaken using the technique of specification. ${ }^{18}$

Principles and Principlism (see also:

Beneficence, Justice, Nonmaleficence, Prima

facie, Respect for Persons, Specification)

Four prima facie principles remain at the centre of education and debate in bioethics: beneficence, nonmaleficence, respect for persons, and justice. They provide the source of rules for ethical decisions (for example, truth telling, privacy, informed consent, etc). Rules are not deduced from principles (that is, principlism) but rather arise from specification. Users of casuistry may also refer to principles when selecting maxims. ${ }^{4} 18$
Respect for persons (see also: Autonomy, Deontological, Prima facie, Principles and Principlism)

A prima facie principle in bioethics underlying the obligation for informed consent in research and decisions regarding study design and interventions. From the Kantian tradition: persons should be treated as ends in themselves and not as means to an end. Implies two distinct moral requirements: acknowledge autonomy and protect those with diminished autonomy. ${ }^{46}$

\section{Rights}

Justified claims made by individuals or groups upon others and based on a system of rules authorising us to affirm or demand what is due. Possessing a right validly constrains others from interfering with the exercise of that right. Moral rights are claims justified by moral principles and are correlated with obligations. In public health, a broadly defined set of human rights are often asserted. ${ }^{19} 2021$

Specification (see also: Principles and

Principlism)

A methodological technique for interpreting a more general ethical principle to bring its implications closer to-to better "apply" it to-actions and decisions. Specification may be used to resolve conflicts among, to balance, or to rank principles. In public health, the Precautionary Principle is a specified version of the more general principle of beneficence. ${ }^{12} 2223$

\section{Utility and Utilitarian}

An approach to ethics asserting that one should always strive to produce the greatest possible balance of good over harm. Historically, identified with social reform movements of 18th century England. Classically expressed as the obligation to produce the greatest good for the greatest number; more recent accounts emphasise optimisation of benefits and harms. ${ }^{42021}$

Values

Concepts used to explain how and why things matter. Values are involved wherever we distinguish between things good and bad, better or worse. Values are characterised as scientific, professional, cultural, social, personal, family, religious, and organic (for example, health). Scientific values include: objectivity, accuracy, generalisability, validity and others. Values are pervasive in epidemiology and public health. ${ }^{24-26}$

Virtues

Character traits-not skills nor techniquesthat make an individual a good professional practitioner, and help her to do her work well. For epidemiologists, the virtues of excellence, integrity, honesty, self effacement, and prudence are important examples. Virtue is not easily taught but may be learned by example from mentors. ${ }^{1427}$

1 Blackburn S. Think. New York: Oxford University Press, 1999. 
2 Kant I. Foundations of the metaphysics of morals. Translated with introduction by Beck LW. New York: Liberal Arts with introducti
Press, 1959.

3 Pellegrino ED. Autonomy and coercion in disease prevention and health promotion. Theor Med 1984;5:83-91.

4 Beauchamp TL, Childress JF. Principles of biomedical ethics. 4th ed. New York: Oxford University Press, 1994

5 Frankena WK. Ethics. 2nd ed. Englewood Cliffs, NJ: Prentice-Hall, 1973.

6 The National Commission for the Protection of Human Subjects of Biomedical and Behavioral Research. The Belmont Report: Ethical Principles and Guidelines for the Protection of Human Subjects. Washington DC: Government Printing Office, 1978

7 Pellegrino ED. The origins and evolution of bioethics: some personal reflections. Kennedy Inst Ethics f 1999;9:73-88.

8 Callahan D. Bioethics. In: Reich WT. Encyclopedia of bioethics. New York: MacMillan, 1995:247-56.

9 Weed DL. The merger of bioethics and epidemiology. 7 Clin Epidemiol 1991;44 (suppl I):15-22S.

10 Arras JD. Getting down to cases: the revival of casuistry in bioethics. F Med Philos 1991;16:29-51.

11 Jonsen AR, Toulmin S. The abuse of casuistry. Berkeley: Uni-

12 DeGrazia D. Moving forward in bioethical theory: theories, cases, and specified principlism. F Med Philos 1992;17:51139.

13 Iltis AS. Specification, specified principlism, and casuistry. $\mathcal{F}$ Med Philos 2000;25:271-360.

14 MacIntyre A. After virtue. 2nd ed. Notre Dame: University Press, 1984.
15 Kuczewski MG. Fragmentation and consensus: communitarian and casuist bioethics. Washington DC: Georgetown University, 1997

16 Nozick R. Anarchy, state, and utopia. New York: Basic, 1974

17 Rawls J. A theory of justice. Revised ed. Cambridge, MA Belknap Press of Harvard University, 1999.

18 Beauchamp TL. The four principles approach. In: Gillon R. Principles of health care ethics. Chichester: Wiley, 1994:3-12

19 Mann J. Human rights and the new public health. Health Hum Rights 1995;1:229-33.

20 Bentham J. An introduction to the principles of morals and legislation. In: Burns JH, Hart HLA, eds. Oxford: Clarendon Press, 1996.

21 Mill JS. Utilitarianism. In: Crisp R, ed. New York: Oxford Press, 1998.

22 Veatch RM. Resolving conflicts among principles: ranking, balancing, and specifying. Kennedy Inst Ethics 7 1995;5: 199-218.

23 Richardson HS. Specifying, balancing and interpreting bioethical principles. $\mathcal{F}$ Med Philos 2000;25:285-307.

24 Susser M, Stein Z, Kline J. Ethics in epidemiology. Ann Am Acad Pol Soc Sci 1978;437:128-41.

25 Longino HE. Science as social knowledge: values and objectivity in scientific inquiry. Princeton: University Press, 1990.

26 Ogletree TW. Values and valuation. In: Reich WT. Encyclopedia of bioethics. New York: MacMillan, 1995: 2515-20.

27 Weed DL, McKeown RE. Epidemiology and virtue ethics. Int f Epidemiol 1998;27:343-8.

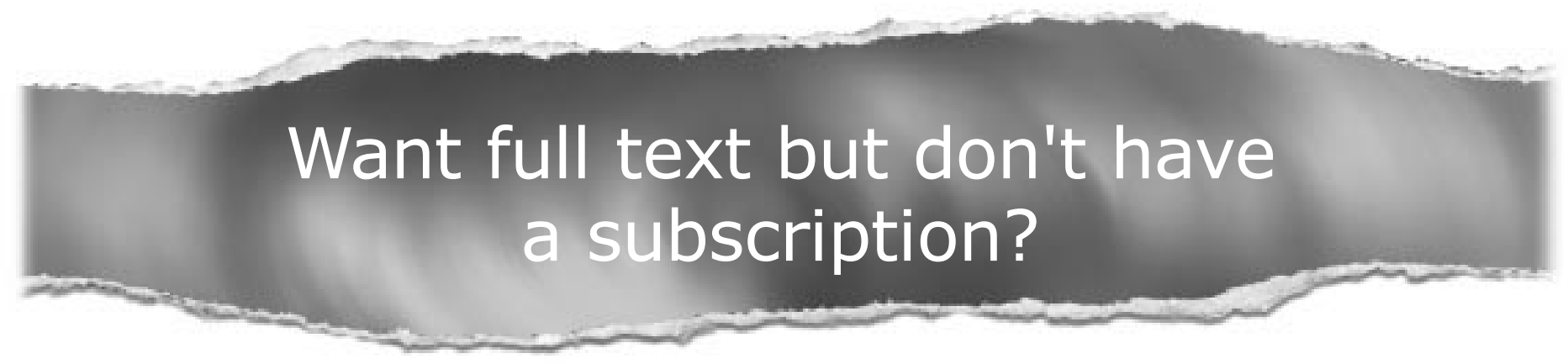

\section{Pay per view}

For just $\$ 8$ you can purchase the full text of individual articles using our secure online ordering service. You will have access to the full text of the relevant article for 48 hours during which time you may download and print the pdf file for personal use.

\section{www.jech.com}

